\title{
Editorial
}

\section{Impact factor of the journal citation reports (JCR) and QUALIS CAPES in Food Science and Technology}

Six Brazilian scientific journals were suspended from the Journal Citation Reports (JCR) published by Thomson Reuters, one of the main indexes that assess the impact factor of scientific journals (the number of quotes of published papers). The cause was irregularities in citations. The Impact Factor, one of the more common criteria in measuring scientific articles, consists of the mean of citations per article during a certain time interval. Although the model is highly criticized, it is usual to associate the Impact Factor with the journal's prestige. Thomson Reuters, the JCR organizer, states that certain Brazilian journals have used the stacking scheme, a type of cross-citation, to swell the Impact Factor. Journal A cites journal B which, in its turn, cites journal A, resulting in an inflation of citations. Owing to the above, the Brazilian Association of Scientific Editors (ABEC) and SciELO have published the following note: "ABEC and SciELO reiterate their claims against this and any non-ethical practice in scientific works, and recommend that institutions which publish scientific journals and their editors that these anomalies should be duly investigated and, if applicable, removed. The bad use of the Impact Factor in the evaluation of Brazilian research has during the last years disrupted the true meaning of the index and produced a black spot in the development of journal publishing. However, although evaluation policies in Brazilian research make difficult the progress of our journals, nothing justifies wily and crafty acts to increase the Impact Factor. It should be underscored that journal editors are the main caretakers to ensure compliance with ethical canons in scientific research publications. ABEC and SciELO are duty bound to strengthen capacitation activities and ethical procedures as an integral part of their development program for Brazilian scientific journals so that they may play their relevant role in the advancement of Brazilian research".

As demonstrated in our previous edition (FURLONG; DE SOUZA, 2013), we expect an increase in the Impact Factor in the Journal of Citation Reports (JCR), which was 0.221 and rose to 0.326 in the most recent number of the JCR. This was due to a significant increase in the number of citations.

Unfortunately, the QUALIS CAPES concept in Food Science and Technology was lowered from B2 to B3, due to a rather long interval between the month of publication and that of paper submission. When ahead of print published articles for Food Science and Technology number 3 of 2013 were analyzed, it was verified that mean time between submission and publication was five months, a rather reasonable interval, when compared to other Brazilian publications. Our greatest problem is peer analysis of submitted papers. Most researchers expect that their articles would be published faster. However, most peers refuse the invitation and papers have to be sent to others. This takes time and raises the interval between the paper's acceptance and its publication.

We will endeavor to increase the QUALIS CAPES mark in this field of research and a greater valorization of the single Brazilian journal specific to this area of knowledge. In fact, Food Science and Technology has a relatively good Impact Factor; it is published in English; it is indexed by ISI and SCOPUS. It should be remarked that by the QUALIS mark for Chemistry, the journal would have a B5 concept (B5 journals with Impact Factor lower than 0.5 but equal to and higher than 0.1) but a B3 concept was given to the Food Science and Technology with the following comment: "Due to our policy for the valorization of quality scientific journals edited by Brazilian scientific societies, the B3 concept was awarded to Food Science and Technology".

I would also invite all researchers involved in our journal Food Science and Technology to effectively play their role as peers and to be members of the Brazilian Society for Food Science and Technology so that our society will continue to be a strong and united community with relevant importance in Brazil.

Nilson Evelázio de Souza Chief Editor of Food Science and Technology

Eliane Badiale Furlong Deputy Editor of Food Science and Technology

\section{References}

FURLONG, E. B.; DE SOUZA, N. E. The scientific journal 'Ciência e Tecnologia de Alimentos' internationalizes its name to Food Science and Technology. Food Science and Technology, v. 33, p. 225, 2013. 